\title{
Trabalho e Consumo: Proposta de Discussão acerca das Definições sobre o Processo de Co-criação
}

\section{Work and Consumption: Discussing the Definitions about the Process of Co-creation}

\author{
Rosana Córdova Guimarães ${ }^{1}$ \\ ${ }^{1}$ Universidade Federal do Rio Grande do Sul, URGS, Brasil. \\ Correspondência: Rosana Córdova Guimarães. Av. Paulo Gama, 110, Farroupilha, CEP 90.040-060, Porto Alegre, \\ RS, Brasil. Telefone: +55 (51) 3308-6000. E-mail: guimaraes.rosana@gmail.com.
}

Recebido: 24 de abril de 2018 Aceito: 19 de outubro de 2018 Publicado: 28 de dezembro de 2018

DOI: http://dx.doi.org/10.21714/1679-18272018v16n1.p78-86

\begin{abstract}
Resumo
O objetivo deste artigo é apresentar uma discussão inicial, de natureza teórica, sobre as diferentes nomenclaturas que emergem no campo do Marketing, Marketing Crítico e Estudos Organizacionais acerca do processo de cocriação. Em literatura recente, observa-se a existência de definições como prosumer, públicos produtivos, trabalho organizacional, free labor e crowdsourcing. Partindo do pressuposto que cada definição busca, a seu modo, explicar as novas relações entre trabalho e consumo, elaborou-se um quadro teórico organizador dos elementos-chave que compõe cada conceito. O quadro-síntese revela um campo de estudos ainda em construção, onde um mesmo conceito acerca da co-criação pode ter diferentes interpretações. Sugere-se que trabalhos futuros busquem ampliar o escopo da pesquisa, agregando mais definições.
\end{abstract}

Palavras-chave: Trabalho, Consumo e Co-criação.

\begin{abstract}
The purpose of this article is to present an initial theoretical discussion about the different nomenclatures that emerge in the field of Marketing, Critical Marketing and Organizational Studies about the co-creation process. In recent literature, there are definitions such as prosumer, productive audiences, organizational work, free labor and crowdsourcing. Based on the assumption that each definition seeks, in its own way, to explain the new relations between work and consumption, a theoretical framework was organized with the key aspects that defines each concept. The synthesis table reveals a field of studies that is still under construction, where the same concept of co-creation may have different interpretations. It is suggested that future researches seek to broaden the scope of the research, adding more definitions.
\end{abstract}

Keywords: Work; Consumption, Cocreation.

Esta obra está licenciada sob uma Licença Creative Commons Attribution 3.0

\section{Introdução}

O principal objetivo do presente artigo é discutir as diferentes nomenclaturas que emergem no campo de Marketing, Marketing Crítico e Estudos Organizacionais acerca do processo de co-criação. É possível observar em literatura recente a existência de definições como prosumer (FONTENELLE, 2015a; 2015b; RITZER, 2014), públicos produtivos (ARVIDSSON, 2010; 2013), trabalho organizacional (DUJARIER, 2014), free labor (TERRANOVA, 2000; 2013) e crowdsourcing (BAUER; GEGENHUBER, 2015), que buscam, cada uma a seu modo, dar conta do pressuposto que o consumidor e o consumo contemporâneos não podem ser compreendidos separadamente do mundo do trabalho e da produção (ver GABRIEL; LANG, 2008; HARVEY, 2011; MARX, 1971; RITZER, 2014).

No entanto, não parece existir um consenso sobre sua real definição, ou seja, existem autores que se inclinam para a argumentação de que o processo de co-criação é entendido, por exemplo, como algo benéfico para empresas e consumidores (ver PRAHALAD; RAMASWAMY, 2004a; 2004b) e outros que apontam, a partir de uma visão 
mais crítica, para a alienação do consumidor durante este processo (ver COMOR, 2010a, 2010b) e também que existe um trabalho não remunerado sendo realizado pelo consumidor (ver TERRANOVA, 2000; 2013; ANDREJEVIC, 2013; HESMONDHALGH, 2010).

A justificativa para esse estudo encontra respaldo nas transformações que vem ocorrendo no capitalismo contemporâneo (ver BOLTANSKI; CHIAPELLO, 2002; HARVEY, 2011) que exige dos indivíduos novas maneiras de trabalhar e viver (ver PELBART, 2011; LAZZARATO, 2006). De acordo com Pelbart (2011), o trabalho dito 'imaterial', que produz principalmente informação, conhecimento e imagens, extrapola o tempo de trabalho para coincidir com o tempo de vida. $\mathrm{O}$ que se percebe é que cada vez mais o "trabalho contemporâneo aparece como atividade produtiva da multidão, de sua inteligência coletiva, de sua paixão, afetividade, inventividade, em suma, de sua vitalidade" (PELBART, 2011, p. 84).

Embora Alvin Toffler (1980), na obra A Terceira Onda, possa ser considerado pioneiro na criação do termo Prosumer, outros autores, explicitados no início desse artigo, também têm desenvolvido trabalhos dentro desta temática. Assim, as interfaces entre trabalho e consumo têm aparecido sob diversas formas e conceitos. Para um maior esclarecimento, elaboramos um quadro-síntese que resume os diferentes termos que vêm sendo discutidos em trabalhos recentes, seus autores, respectivas publicações e como cada termo é conceituado dentro da literatura apontada:

Quadro 1: Quadro-síntese.

\begin{tabular}{|c|c|c|c|c|}
\hline Termo & Autor & Livro/Artigo/Journal & $\begin{array}{l}\text { Ano de } \\
\text { publicação }\end{array}$ & Conceito \\
\hline \multirow{6}{*}{ Prosumer } & Alvin Toffler & A Terceira Onda & 1980 & $\begin{array}{l}\text { A Terceira Onda (transformações } \\
\text { tecnológicas e informacionais) } \\
\text { promove uma não-separação entre } \\
\text { produção e consumo. }\end{array}$ \\
\hline & $\begin{array}{l}\text { George Ritzer, } \\
\text { Nathan } \\
\text { Jurgenson }\end{array}$ & $\begin{array}{l}\text { Production, } \\
\text { consumption, } \\
\text { prosumption: the } \\
\text { nature of capitalism in } \\
\text { the age of the digital } \\
\text { 'prosumer' }\end{array}$ & 2010 & \multirow{2}{*}{$\begin{array}{l}\text { Com base em Toffler, porém em } \\
\text { versão mais atual, propõe-se uma } \\
\text { redefinição de produção e } \\
\text { consumo, como um continuum. } \\
\text { Produção é entendida como } \\
\text { "prosumption-as-production" } \\
\text { consumo como "prosumption-as- } \\
\text { consumption". }\end{array}$} \\
\hline & George Ritzer & $\begin{array}{l}\text { Prosumption: } \\
\text { evolution, revolution, } \\
\text { or eternal return to the } \\
\text { same? - Journal of } \\
\text { Consumer Culture } \\
\end{array}$ & 2014 & \\
\hline & \multirow[b]{2}{*}{$\begin{array}{l}\text { Edward } \\
\text { Comor }\end{array}$} & $\begin{array}{l}\text { Digital prosumption } \\
\text { and alienation - } \\
\text { Ephemera }\end{array}$ & $2010 \mathrm{a}$ & \multirow{2}{*}{$\begin{array}{l}\text { A partir de lentes marxistas, o autor } \\
\text { afirma que é ilusória a ideia que o } \\
\text { prosumer está consciente e sob } \\
\text { controle das suas atividades de } \\
\text { produção e consumo. O prosumer } \\
\text { ainda serve, na sua maioria, } \\
\text { interesses que mantêm o status quo } \\
\text { vigente. }\end{array}$} \\
\hline & & $\begin{array}{lr}\text { Contextualizing and } \\
\text { critiquing the fantastic } \\
\text { prosumer: } \\
\text { alienation } & \text { power, } \\
\text { hegemony } & \text { - } \\
\text { Socitical } \\
\text { Sociology }\end{array}$ & $2010 b$ & \\
\hline & $\begin{array}{l}\text { Isleide } \\
\text { Fontenelle }\end{array}$ & 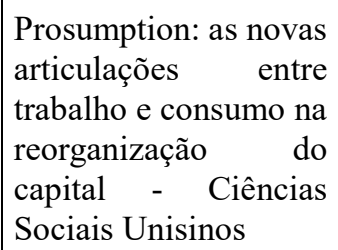 & $2015 b$ & $\begin{array}{l}\text { O consumidor tem se tornado cada } \\
\text { vez mais engajado no valor do } \\
\text { processo de produção. Nesta } \\
\text { perspectiva, o consumo pode ser } \\
\text { considerado investimento no } \\
\text { trabalho. }\end{array}$ \\
\hline
\end{tabular}




\begin{tabular}{|c|c|c|c|c|}
\hline & & $\begin{array}{lr}\text { Organisations } & \text { as } \\
\text { producers } & \text { of } \\
\text { consumers } & - \\
\text { Organization } & \end{array}$ & $2015 \mathrm{a}$ & \\
\hline \multirow{3}{*}{ Free Labor } & $\begin{array}{l}\text { Mark } \\
\text { Andrejevic }\end{array}$ & $\begin{array}{l}\text { Estranged Free Labor } \\
\text { - Digital Labor: the } \\
\text { internet as playground } \\
\text { and social factory }\end{array}$ & 2013 & \multirow{3}{*}{$\begin{array}{l}\text { Visão crítica sobre o Trabalho } \\
\text { Digital. O futuro da internet está } \\
\text { centrado na exploração da } \\
\text { participação ativa dos usuários. }\end{array}$} \\
\hline & $\begin{array}{l}\text { David } \\
\text { Hesmondhalgh }\end{array}$ & $\begin{array}{l}\text { User-Generated } \\
\text { Content, Free Labour } \\
\text { and the Cultural } \\
\text { Industries - Ephemera }\end{array}$ & 2010 & \\
\hline & $\begin{array}{l}\text { Tiziana } \\
\text { Terranova }\end{array}$ & $\begin{array}{l}\text { Free Labor: producing } \\
\text { culture for the digital } \\
\text { economy - Social Text }\end{array}$ & 2000 & \\
\hline \multirow{2}{*}{ Crowdsourcing } & $\begin{array}{l}\text { Robert Bauer, } \\
\text { Thomas } \\
\text { Gegenhuber }\end{array}$ & $\begin{array}{l}\text { Crowdsourcing: } \\
\text { global search and the } \\
\text { twisted roles of } \\
\text { consumers r and } \\
\text { producers } \\
\text { Organization }\end{array}$ & 2015 & $\begin{array}{l}\text { Forma de inovação open source que } \\
\text { vem sendo utilizada por empresas } \\
\text { de software nos últimos anos. Para } \\
\text { os autores, o crowdsourcing muda a } \\
\text { o foco das multidões como } \\
\text { entidades sociopolíticas para } \\
\text { multidões como fontes de valor } \\
\text { econômico. }\end{array}$ \\
\hline & $\begin{array}{l}\text { Frank } \\
\text { Kleemann, G. } \\
\text { Günter Voß, } \\
\text { Kerstin Rieder }\end{array}$ & $\begin{array}{l}\text { Un(der)paid } \\
\text { Innovators: the } \\
\text { commercial utilization } \\
\text { of consumer work } \\
\text { through } \\
\text { crowdsourcing - } \\
\text { Science, Technology } \\
\text { \& Innovation Studies }\end{array}$ & 2008 & $\begin{array}{l}\text { Crowdsourcing representa a forma } \\
\text { mais explícita de integração de } \\
\text { usuários (ou consumidores) nos } \\
\text { processos internos de criação de } \\
\text { valor e possibilita a utilização direta } \\
\text { do trabalho do consumidor para } \\
\text { propósitos comerciais. }\end{array}$ \\
\hline \multirow[t]{2}{*}{ Co-criação } & \multirow{2}{*}{$\begin{array}{l}\text { C. K. Prahalad, } \\
\text { Venkat } \\
\text { Ramaswamy }\end{array}$} & $\begin{array}{l}\text { Co-creation } \\
\text { experiences: the next } \\
\text { practice in value } \\
\text { creation - Journal of } \\
\text { Interactive Marketing } \\
\end{array}$ & 2004 & \multirow{2}{*}{$\begin{array}{l}\text { Criação de valor realizada pela } \\
\text { empresa e pelo consumidor. } \\
\text { Permite que o consumidor co- } \\
\text { construa a experiência de serviços } \\
\text { mais adequado para o seu contexto. }\end{array}$} \\
\hline & & $\begin{array}{l}\text { The future of } \\
\text { competition: co- } \\
\text { creating unique value } \\
\text { with customers }\end{array}$ & 2004 & \\
\hline
\end{tabular}


Guimarães, R. C..

\begin{tabular}{|c|c|c|c|c|}
\hline & $\begin{array}{l}\text { Detlev Zwick, } \\
\text { Samuel Bonsu, } \\
\text { Aron Darmody }\end{array}$ & $\begin{array}{l}\text { Putting Consumers to } \\
\text { Work: 'co-creation' } \\
\text { and new marketing } \\
\text { govern-mentality - } \\
\text { Journal of Consumer } \\
\text { Culture }\end{array}$ & 2008 & $\begin{array}{l}\text { A partir da obra de Prahalad e } \\
\text { Ramaswamy, os autores examinam } \\
\text { e questionam o projeto de } \\
\text { marketing que reconfigura a } \\
\text { produção do valor de uso e valor de } \\
\text { troca. Para os autores, as } \\
\text { tecnologias fazem a mediação da } \\
\text { interação social de modo que } \\
\text { competências cognitivas, sociais e } \\
\text { afetivas do trabalhador são } \\
\text { integradas ao processo de trabalho. }\end{array}$ \\
\hline \multirow{3}{*}{$\begin{array}{l}\text { Públicos } \\
\text { produtivos/Economia } \\
\text { Ética }\end{array}$} & $\begin{array}{l}\text { Adam } \\
\text { Arvidsson, } \\
\text { Nicolai } \\
\text { Peiterson }\end{array}$ & $\begin{array}{l}\text { The Ethical Economy } \\
\text { - Rebuilding Value } \\
\text { after the Crisis }\end{array}$ & 2013 & \multirow{3}{*}{$\begin{array}{l}\text { Os autores partem do conceito de } \\
\text { públicos produtivos para propor } \\
\text { dois domínios distintos de } \\
\text { circulação de valor: o tradicional, } \\
\text { monetário, e o ético, através da } \\
\text { reputação - chamado por eles de } \\
\text { Economia Ética. }\end{array}$} \\
\hline & \multirow{2}{*}{$\begin{array}{l}\text { Adam } \\
\text { Arvidsson }\end{array}$} & $\begin{array}{l}\text { The Ethical Economy } \\
\text { - new forms of value } \\
\text { in information } \\
\text { society? } \\
\text { Organization }\end{array}$ & 2010 & \\
\hline & & $\begin{array}{l}\text { The Ethical Economy } \\
\text { of Customer } \\
\text { Coproduction } \\
\text { Journal } \\
\text { Macromarketing }\end{array}$ & 2008 & \\
\hline $\begin{array}{l}\text { Consumo } \\
\text { Colaborativo }\end{array}$ & $\begin{array}{l}\text { Rachel } \\
\text { Botsman, Roo } \\
\text { Rogers }\end{array}$ & $\begin{array}{l}\text { What's mine is yours - } \\
\text { How collaborative } \\
\text { consumption is } \\
\text { changing the way we } \\
\text { live. }\end{array}$ & 2011 & $\begin{array}{l}\text { O consumo colaborativo é } \\
\text { entendido um espaço que promove } \\
\text { o surgimento de redes de } \\
\text { empréstimos e compartilhamentos, } \\
\text { fazendo com que as pessoas passem } \\
\text { de consumidores passivos para } \\
\text { colaboradores ativos. }\end{array}$ \\
\hline Sharing Economy & $\begin{array}{l}\text { Philippe } \\
\text { Aigrain, } \\
\text { Suzanne } \\
\text { Aigrain }\end{array}$ & $\begin{array}{l}\text { Sharing - Culture and } \\
\text { the Economy in the } \\
\text { Internet Age }\end{array}$ & 2012 & $\begin{array}{l}\text { Discussão sobre o conceito de } \\
\text { Sharing, entendido com algo útil e } \\
\text { legítimo que ganhou força na Era da } \\
\text { Internet. }\end{array}$ \\
\hline $\begin{array}{l}\text { Trabalho } \\
\text { Organizacional }\end{array}$ & $\begin{array}{l}\text { Marie-Anne } \\
\text { Dujarier }\end{array}$ & $\begin{array}{l}\text { The tree sociological } \\
\text { types of consumer } \\
\text { work - Journal of } \\
\text { Consumer Culture }\end{array}$ & 2014 & $\begin{array}{l}\text { A autora identifica uma terceira } \\
\text { forma de trabalho em que o } \\
\text { consumidor é convidado a provar, } \\
\text { tentar e experimentar novos } \\
\text { produtos. O consumidor contribui, } \\
\text { mediante nenhum pagamento, para } \\
\text { criar confiança nos mercados. }\end{array}$ \\
\hline Comunidade & Detlev Zwick & $\begin{array}{l}\text { Utopias of ethical } \\
\text { economy: a response } \\
\text { to Adam Arvidsson }\end{array}$ & 2013 & $\begin{array}{l}\text { O autor critica a proposta de } \\
\text { Economia Ética realizada por } \\
\text { Arvidsson, afirmando ser ingênua, } \\
\text { pois não vai a fundo na natureza do } \\
\text { trabalho do público consumidor e } \\
\text { seria apenas uma extensão da lógica } \\
\text { neoliberal. Sugere que seja buscada } \\
\text { uma melhor definição de } \\
\text { 'comunidade', que a seu ver é } \\
\text { utilizado de maneira indiscriminada } \\
\text { na literatura. }\end{array}$ \\
\hline
\end{tabular}

Fonte: Elaborado pela autora. 
Conforme podemos observar no quadro acima, existem conceitos que se assemelham em alguns aspectos e outros que, apesar de utilizarem o mesmo termo, se distanciam na definição. De maneira breve, é o que será discutido a seguir:

\section{Prosumer}

É possível afirmar que, durante a Primeira Onda (TOFFLER, 1980), a maioria das pessoas consumia o que era produzido por elas, não sendo produtores ou consumidores no sentido usual da palavra. Eles poderiam ser chamados de prosumidores. Foi durante a Segunda Onda que se observou a separação da atividade em produção e consumo, e essa separação levou ao sistema de mercados, redes de trocas e canais pelos quais bens e serviços são distribuídos (TOFFLER, 1980).

Mas como podemos definir esse novo momento do prosumer, em que as fronteiras entre produção e consumo estão cada vez mais borradas? (TOFFLER, 1980; RITZER, DEAN; JURGENSON, 2012; RITZER, 2014; GABRIEL, LANG, 2008; HUMPHREYS; GRAYSON, 2008). De acordo com Toffler (1980), o surgimento do prosumer traz uma mudança fundamental nas relações entre setor A e setor B, transformando os papéis dos mercados na sociedade.

A partir de Toffler, autores contemporâneos têm se debruçado em desenvolver o tema:

- Na visão de Ritzer (2014), enfatiza-se a importância crescente do consumo depois da Segunda Guerra Mundial, sendo que o trabalho de Baudrillard (2005) foi decisivo para a mudança de foco. Ritzer (2014) enxerga o prosumption como um 'continuum', ou seja, para ele não existem 'tipo ideais' (WEBER, 2004). Para o autor, de certo modo, sempre fomos 'prosumers': "nós somos prosumers antes mesmo de existir uma distinção entre produtores e consumidores, prosumption é nossa condição primeira" (RITZER, 2014, p. 18).

- Olhar de Comor (2010a, 2010b) sobre prosumer repousa na conceitualização de Marx sobre alienação, em que as pessoas são compelidas a se tornar meras ferramentas de um processo de produção. Ainda que pareça que o prosumer está ciente e sob o controle de suas atividades relacionadas à produção e consumo, até mesmo de maneira livre e autônoma, o prosumer ainda mostra-se dependente de empresas que comandam as infraestruturas essenciais nas quais as pessoas produzem e consomem, restando pouco espaço para uma autonomia genuína.

- $\quad$ Fontenelle $(2015 \mathrm{a}, 2015 \mathrm{~b})$ aponta lacunas na literatura sobre o prosumption de que faltam análises sobre como o trabalho pode se tornar consumo. A autora cita como referências os estudos de López-Ruiz (2009), que discute como o trabalhador tem consumido como um modo de investir em si mesmo e de Abílio (2011). Abílio (2011), a partir da pesquisa realizada com as consultoras da empresa de cosméticos brasileira Natura, chegou à conclusão que elas consomem produtos da marca para realizar trabalho, revelando também o embaralhamento das fronteiras entre tempo de trabalho e de não-trabalho, a partir da esfera do consumo (FONTENELLE, 2015b).

\section{Públicos produtivos e Economia ética}

Uma linha de raciocínio levantada principalmente por Arvidsson (ARVIDSSON, 2008, 2010; ARVIDSSON; COLLEONI, 2012; ARVIDSSON; PEITERSEN, 2013) é de que esse processo de coprodução está intimamente relacionado com o que ele chamou de Economia Ética. O processo de "co-criar consumidores se constitui como uma externalidade positiva para os negócios e uma significativa, ainda que difícil de mesurar, fonte de receita econômica" (ARVIDSSON; MALOSSI, 2011). Dessa forma, há uma mudança nas práticas de negócios e de marketing que deixam apenas de vender coisas que são produzidas para "destrancar o potencial produtivo dos relacionamentos" (ARVIDSSON; MALOSSI, 2011; ZWICK; OZALP, 2011).

Para Arvidsson (2008), há um aumento progressivo da inclusão de consumidores nos processos onde o valor é produzido em torno de produtos e marcas, ou seja, "cada vez mais as empresas envolvem seus consumidores na coprodução de marcas, experiências, design, estratégias de marketing e até mesmo desenvolvimento de produto" (ARVIDSSON, 2008, p. 326). O autor acredita que essa tendência se desenvolverá com mais força no futuro em função principalmente do avanço da internet.

Um dos pilares da Economia Ética proposta por Arvidsson $(2008$; 2010; 2013) se sustenta no fato de que seria necessário a existência de uma nova estrutura institucional em torno do conceito de valor, baseando-se nas seguintes premissas: (1) públicos produtivos como um caminho para a criação de riqueza na economia; (2) sistemas financeiros que tomam decisões em um contexto de cadeias de valor globais e em rede; (3) uma nova "economia da reputação", entendida como um "componente natural” (ARVIDSSON; PEITERSEN, 2013, p. 137) no desenvolvimento de públicos produtivos. 
O raciocínio elaborado por Arvidsson $(2008 ; 2010 ; 2013)$ em torno dos públicos produtivos e da economia ética gerou uma resposta, em formato de artigo, por Zwick (2013). Embora Zwick (2013) reconheça o esforço de Arvidsson $(2008 ; 2010 ; 2013)$ em elaborar um conceito de público consumidor como um lugar de consumo de produção colaborativa, ele questiona se essa nova racionalidade ética - onde reside a "economia da reputação" não seria, na verdade, um espaço em que "o produtor-consumidor de conhecimento (knowledge producerconsumer) se torna um empreendedor de si mesmo" (ZWICK, 2013, p. 399). A crítica de Zwick, de certo modo, conecta-se com a análise desenvolvida por Fontenelle (2015a) sobre o consumo ser também uma forma de investimento.

A partir da crítica ao conceito de Arvidsson (2008; 2010; 2013), Zwick (2013) chama a atenção para o fato de que existe uma lacuna teórica do conceito de "comunidade", que é utilizado de maneira indiscriminada e descreve quase todo o tipo de associação de indivíduos em rede.

No tópico a seguir será apresentado o conceito proposto por Dujarier (2014), denominado Trabalho Organizacional, em conjunto com a discussão de Terranova (2000; 2013) e Andrejevic (2013) e Hesmondhalgh (2010) sobre Free Labor.

\section{Trabalho Organizacional e Free Labor}

Em artigo recente, Dujarier (2014) afirma que atualmente existem 3 configurações sociais em que o consumidor é colocado para trabalhar: (1) através da produção própria direta, em que algumas tarefas simples são externalizadas e realizadas pelo consumidor, (2) o recente termo co-produção colaborativa e (3) um novo arranjo identificado pela autora e por ela denominado trabalho organizacional.

A terceira forma identificada por Dujarier (2014) é denominada "trabalho organizacional". A autora vai explicar que esse tipo de trabalho se caracteriza pelos "consumidores sendo cada vez mais chamados para provar, tentar e experimentar novos produtos, (...) sendo convidados a participar de atividades estratégicas e testes antes do lançamento de uma nova empresa ou da inovação de produto, software ou design" (DUJARIER, 2014, p. 10). O consumidor contribui, mediante nenhum pagamento (ARVIDSSON, 2006), para criar confiança nos mercados, podendo isso ser visto na classificação de produtos e "lista de favoritos" (DUJARIER, 2014). A questão é que "em todas as situações, o consumidor produz voluntariamente e sem ganhar pagamento algum, bens imateriais para criar valor para a empresa" (DUJARIER, 2014, p. 10).

O trabalho de Dujarier (2014) nos mostra que os consumidores têm assumido uma crescente parte de tarefas consideradas produtivas e que as empresas, cientes disso, têm tirado vantagem das atividades realizadas por consumidores. Nessa mesma vertente, encontra-se a perspectiva crítica denominada Free Labor (TERRANOVA, 2000).

O conceito de Free Labor para Terranova (2013, p. 37) "é o momento onde o consumo bem informado da cultura é traduzido em excesso de atividades produtivas que são prazerosamente abraçadas e, ao mesmo tempo, com frequência exploradas descaradamente". A autora, assim como Andrejevic (2013) e Hesmondhalgh (2010), partem das novas tecnologias da Era da Internet para compreender como as mídias digitais fomentam novas formas de criatividade e participação, mesmo que muitas vezes isso seja realizado em plataformas privadas como, por exemplo, o Facebook e o YouTube (ANDREJEVIC, 2013).

O fato é que a terceira configuração identificada por Dujarier (2014) como Trabalho Organizacional enfatiza o caráter gratuito das atividades realizadas, de uma maneira crítica, assim como o conceito de Free Labor (ANDREJEVIC, 2013; HESMONDHALGH, 2010; TERRANOVA, 2000; 2013).

O próximo item irá discutir aspectos relacionados às definições de Sharing Economy, Consumo Colaborativo e Co-criação.

\section{Sharing Economy, Consumo Colaborativo e Co-criação}

Existe uma literatura (TAPSCOTT; WILLIAMS, 2010; AIGRAIN; AIGRAIN, 2012; BOTSMAN; ROGERS, 2011; PRAHALAD; RAMASWAMY, 2004), que faz uso dos termos Sharing Economy, consumo colaborativo e co-criação sem necessariamente atrelá-los a uma perspectiva crítica que se proponha a analisar aspectos relacionados à exploração e precariedade do trabalho (GILL; PRATT, 2008), por exemplo.

Esse modelo de colaboração em massa (TAPSCOTT; WILLIAMS, 2010) e a capacidade de inovar para criar valor (TAPSCOTT; WILLIAMS, 2010; PRAHALAD; RAMASWAMY, 2004), em geral é celebrada a partir de empresas e casos de sucesso. Basta pensarmos nos exemplos já conhecidos do público como o AirBnB (para acessar quartos nos mais diversos lugares do mundo) e o Uber (serviço de táxi ad hoc). Essas two-sided plataformas oferecem vantagens por desbloquear o valor inerente ao compartilhamento de recursos com pessoas que as desejam (MALHOTRA; VAN ALSTYNE, 2014). 
Porém, de tempos em tempos surgem reportagens que provocam discussões sobre esse modelo de negócios: (1) em Berlim ${ }^{1}$ (FOLHA DE SÃO PAULO, 2016), os proprietários que desejarem alugar seu imóvel por temporada, só poderão disponibilizar $50 \%$ da área da casa ou apartamento. A medida tem por objetivo evitar que os aluguéis pagos mensalmente sejam inflacionados para os cidadãos; (2) em São Paulo² (PORTAL G1, 2016), após inúmeras discussões e protestos por parte dos taxistas, o sistema Uber foi regulamentado pela prefeitura da cidade.

De qualquer maneira, existem autores que trazem o conceito de co-criação com um olhar crítico: Zwick et al. (2008, p. 168) nos mostra como pessoas da área de marketing "tipicamente consideram ter relacionamentos com consumidores como algo que as empresas deveriam aspirar, pois boas relações se traduzem em lucros mais altos". A partir de uma desconstrução sobre a invenção das "relações com o consumidor" no pensamento do marketing, Zwick et al. (2008) se afasta do conceito de co-criação de Prahalad e Ramaswamy (2004) para encontrar diálogos que conceituam a co-criação a partir da lógica geral de produção nas economias informacionais capitalistas (TERRANOVA, 2000, 2013; HESMONDHALGH, 2010) e nas teorizações críticas sobre valor da marca (ARVIDSSON, 2006).

De acordo com Zwick (2008, p. 182), a "noção de co-criação representa uma tecnologia sofisticada de governar os consumidores onde a mais-valia gerada é baseada na apropriação frequente do trabalho criativo em rede e socialmente cooperativo dos consumidores". Ainda assim, tendo esse conceito em mãos e sabendo da sua importância, isso ainda se constitui como uma fronteira não totalmente ultrapassada, ainda que se busque reiteradamente um maior controle sobre os mercados (ZWICK, 2008). A seguir, no próximo item serão discutidas as definições de crowdsourcing.

\section{Crowdsourcing}

O termo Crowdsourcing foi visto pela primeira vez na revista Wired, em junho de 2006, quando o jornalista Jeff Howe fez a junção das palavras crowd e (out-) sourcing (BAUER; GEGENHUBER, 2015). Quando o termo surgiu, não se sabia ao certo o quanto ele iria durar, mas ao explorar a dinâmica fundamental de um mundo em rede, ou seja, trabalhos podem ser realizados em algum lugar, por alguma pessoa, por um certo preço, o crowdsourcing sobreviveu ao seu próprio modismo (HOWE, 2008).

Pensando no contexto de "crowds" e "crowdsourcing", Bauer e Gegenhuber (2015) explicam que há diferenças: em geral, uma "crowd" agindo coletivamente geralmente é vista como uma fonte de agitação social (protestos, mobs) ou como progresso social (greves legítimas). Já no contexto de crowdsourcing, o significado é outro, e geralmente se refere a uma audiência massiva que é alcançável através de um canal de comunicação, tornando-se fontes para o desenvolvimento e produção de bens e serviços. Em resumo, pode-se dizer que o "crowdsourcing muda o foco das multidões como entidades sociopolíticas para multidões como fontes de valor econômico" (BAUER; GEGENHUBER, 2015, p. 664).

O Crowdsourcing gera valor a partir da canalização do excesso de capacidades da sociedade desenvolvimento e produção de bens e serviços (BAUER; GEGENHUBER, 2015). Para Aytes (2013), ele pode ser entendido como uma alternativa aos métodos empregatícios vigentes, assim como um retorno não esperado do conceito de públicos/multidão às discussões globais.

\section{Considerações Finais}

Na introdução deste artigo apresentamos a importância em discutir as diferentes definições que emergem no campo dos estudos de Marketing Crítico e dos Estudos Organizacionais acerca dos processos de co-criação e como tal fato está relacionado com as novas formas de trabalho e consumo nas sociedades contemporâneas. Entendemos que o debate sobre trabalho e consumo pode contribuir para uma melhor compreensão da lógica do funcionamento das organizações e da sociedade.

Este trabalho caracteriza-se como um esforço inicial de organização de definições que giram em torno dos processos de co-criação. Mostramos que não existe um consenso e também que um mesmo conceito (por exemplo, prosumer) pode ser enxergado a partir de diversas óticas.

O resultado dessa organização preliminar de conceitos permite uma reflexão sobre as seguintes questões: 1) os processos de co-criação que ocorrem entre organizações e consumidores são positivos ou negativos para a

\footnotetext{
${ }^{1} \mathrm{http} / /$ www1.folha.uol.com.br/turismo/2016/04/1766335-berlim-reforca-cerco-contra-aluguel-por-temporadaem-sites-como-airbnb.shtml

${ }^{2}$ http://g1.globo.com/sao-paulo/noticia/2016/05/haddad-assina-decreto-e-libera-uber-em-sao-paulo.html
} 
sociedade? Será que cabe uma polarização? 2) Como as áreas de Marketing, Marketing Crítico e Estudos Organizacionais poderiam dialogar mais sobre o tema? 3) Quais outras definições estão emergindo no campo e que também dão conta de explicar os fenômenos que envolvem as fronteiras cada vez mais borradas entre trabalho e consumo?

\section{Referências}

ABÍLIO, L. O Make Up do Trabalho: Uma Empresa e um Milhão de Revendedoras de Cosméticos, Tese de Doutorado, Universidade Estadual de Campinas, 2011.

AIGRAIN, P.; AIGRAIN, S. Sharing: culture and the economy in the internet age. Amsterdam: Amsterdam University Press, 2012.

ANDREJEVIC, M. Estranged Free Labor. In: SCHOLZ, T. (Ed.) Digital Labor: the internet as playground and factory. New York: Routledge, 2013.

ARVIDSSON, A. Brands: meaning and value in media culture. London: Routledge, 2006.

326-338.

. The ethical economy of customer coproduction. In: Journal of Macromarketing, v. 28, n. 4, 2008, p.

The ethical economy: new forms of value in the information society? In: Organization, v. 17, n. 5 , 2010, p. 637-644. p. $367-391$.

The potential of consumer publics. In: Ephemera: theory \& politics in organization, v. 13, n. 2, 2013,

ARVIDSSON, A.; COLLEONI, E. Value in Informational Capitalism and on the Internet. In: The Information Society: an International Journal, v. 28, 2012, p. 135-150.

ARVIDSSON, A.; MALOSSI, G. Customer Co-production from Social Factory to Brand: Learning from Italian Fashion. In: ZWICK, D.; CAYLA, J. (Ed.). Inside Marketing - practices, ideologies, devices. Oxford: Oxford University Press, 2011.

ARVIDSSON, A.; PEITERSEN, N. The Ethical Economy: Rebuilding Value after the Crisis. New York: Columbia University Press, 2013.

BAUER, R. M.; GEGENHUBER, T. Crowdsourcing: global search and the twisted roles of consumers and producers. In: Organization, v. 22, n. 5, 2015, p. 661-681.

BOLTANSKI, L.; CHIAPELLO, E. El nuevu espíritu del capitalismo. Madrid: Ediciones Akal, 2002.

BOTSMAN, R.; ROGERS, R. What's mine is yours: how collaborative consumption is changing the way we live. London: Collins, 2011.

COMOR, E. Contextualizing and Critiquing the Fantastic Prosumer: Power, Alienation and Hegemony. In: Critical Sociology, v. 37, n. 3, 2010a, p. 309-327. 2010b, p. 439-454.

Digital prosumption and alienation. In: Ephemera: theory \& politics in organization, v. 10, n. 3-4,

DUJARIER, M. A. The three sociological types of consumer work. In: Journal of Consumer Culture, v. 0, n. 0, 2014, p. 1-17.

FONTENELLE, I. A. A Prosumption: as novas articulações entre trabalho e consumo na reorganização do capital. In: Ciências Sociais Unisinos, v. 51, n. 1, 2015b, p. 83-91.

. Organisations as producers of consumers. In: Organization, v. 22, n. 5, 2015a, p. 644-660.

GABRIEL, Y.; LANG, T. New faces and new masks of today's consumer. In: Journal of Consumer Culture, v. 8, n. 3, 2008, p. 321-340.

GILL, R.; PRATT, A. Precarity and Cultural Work in the Social Factory? Immaterial Labour, Precariousness and Cultural Work. In: Theory, Culture \& Society, v. 25, n. 7-8, 2008, p. 1-30.

HARVEY, D. O enigma do capital e as crises do capitalismo. São Paulo: Boitempo, 2011.

HESMONDHALGH, D. User-generated content, free labour and cultural industries. In: Ephemera, v. 10, n. 3-4, 2010, p. 267-284. 
HOWE, J. Crowdsourcing - why the power of the crowd is driving the future of business. New York: Three Rivers, 2008.

HUMPHREYS, A.; GRAYSON, K. The intersecting roles of consumer and producer: a critical perspective on coproduction, co-creation and presumption. In: Sociology Compass, v. 2, n. 3, 2008, p. 963-980.

KLEEMAN, F.; VOß, G. G.; RIEDER, K. Un(der)paid innovators: the commercial utilization of consumer work through crowdsourcing. In: Science, Technology \& Innovation Studies, v. 4, n. 1, 2008, p. 5-26.

LAZZARATO, M. Immaterial Labor. In: VIRNO, P.; HARDT, M. (Ed.). Radical Thought in Italy: a Potential Politics. United States: University of Minnesota Press, 2006.

LÓPEZ-RUIZ, O. J. O consumo como investimento: a teoria do capital humano como ethos. In: Mediações Revista de Ciências Sociais, v. 14, n. 2, 2009, p, 217-230.

MALHOTRA, A; VAN ALSTYNE, M. The Dark Side of the Sharing Economy... and How to Lighten It. In: Communications of the ACM, v. 57, n. 11, 2014, p. 24-27.

MARX, K. The Grundrisse. New York: Harper \& Row, 1971.

PELBART, P. Vida capital: ensaios de biopolítica. São Paulo: Iluminuras, 2011.

PRAHALAD, C. K.; RAMASWAMY, V. Co-creation experiences: the next practice in value creation. In: Journal of Interactive Marketing, v. 18, n. 3, 2004a, p. 5-14. $2004 b$.

. The future of competition: co-creating unique value with customers. Boston: Harvard University Press,

RITZER, G. Prosumption, evolution, revolution, or eternal return of the same?. In: Journal of Consumer Culture, v. 14, n. 1, 2014, p. 3-24.

RITZER, G.; DEAN, P.; JURGENSON, N. The coming age of the prosumer. In: American Behavioral Scientist, v. 56, n. 4, 2012, p. 379-398.

TASPCOTT, D.; WILLIAMS, A. D. Wikinomics: how mass collaboration changes everything. New York: Portfolio, 2010.

TERRANOVA, T. Free Labor: producing culture for the digital economy. In: Social Text, v. 18, n. 2, 2000, p. 33 58.

Routledge, 2013.

Free Labor. In: SCHOLZ, T. (Ed.) Digital Labor: the internet as playground and factory. New York: TOFFLER, A. The third wave. New York: William Morrow, 1980.

ZWICK, D. Uthopias of ethical economy: a response to Adam Arvidsson. In: Ephemera, v. 13, n. 2, 2013, p. 393405.

ZWICK et al. Putting Consumers to Work: 'Co-creation' and new marketing govern-mentality. In: Journal of Consumer Culture, v. 8, n. 2, 2008, p. 163-196.

ZWICK, D.; OZALP, Y. Flipping the neighborhood: biopolitical marketing as value creation for condos and lofts. In: ZWICK, D.; CAYLA, J. (Ed.). Inside Marketing - practices, ideologies, devices. Oxford: Oxford University Press, 2011. 